\title{
Knockout of an Azorhizobial dTDP-L-Rhamnose Synthase Affects Lipopolysaccharide and Extracellular Polysaccharide Production and Disables Symbiosis with Sesbania rostrata
}

\author{
Mengsheng Gao, * Wim D'Haeze, ${ }^{*}$ Riet De Rycke, Beata Wolucka, and Marcelle Holsters \\ Vakgroep Moleculaire Genetica, Departement Plantengenetica, Vlaams Interuniversitair Instituut voor \\ Biotechnologie (VIB), Universiteit Gent, K.L. Ledeganckstraat 35, B-9000 Gent, Belgium \\ Submitted 18 August 2000; Accepted 19 March 2001.
}

\begin{abstract}
A nonpolar mutation was made in the oac2 gene of Azorhizobium caulinodans. oac2 is an ortholog of the Salmonella typhimurium $r f b D$ gene that encodes a dTDP-Lrhamnose synthase. The knockout of oac2 changed the lipopolysaccharide (LPS) pattern and affected the extracellular polysaccharide production but had no effect on bacterial hydrophobicity. Upon hot phenol extraction, the wild-type LPS partitioned in the phenol phase. The LPS fraction of ORS571-oac2 partitioned in the water phase and had a reduced rhamnose content and truncated LPS molecules on the basis of faster migration in detergent gel electrophoresis. Strain ORS571-oac2 induced ineffective nodule-like structures on Sesbania rostrata. There was no clear demarcation between central and peripheral tissues, and neither leghemoglobin nor bacteroids were present. Light and electron microscopy revealed that the mutant bacteria were retained in enlarged, thick-walled infection threads. Infection centers emitted a blue autofluorescence under UV light. The data indicate that rhamnose synthesis is important for the production of surface carbohydrates that are required to sustain the compatible interaction between $A$. caulinodans and $S$. rostrata.
\end{abstract}

From the rhizobial point of view, the establishment of a successful symbiosis with leguminous host plants depends on the production of Nod factor signals and exposure of the correct surface and/or extracellular polysaccharides (Niehaus and Becker 1998; Price 1999). Whereas the role of Nod factors as triggers of early plant responses is becoming quite well understood, the function of the bacterial envelope and the diverse types of surface polysaccharides (SPS) is far less defined. In several experimental systems, the importance of these classes of molecules for an efficient symbiosis has been demonstrated, but the molecular mechanisms or signaling pathways are not known. SPS have been implied in a multitude of processes such as internalization, suppression of defense responses, triggering of infection thread formation, and elicita-

Corresponding author: M. Holsters; Fax: +32 9 2645349;

E-mail: mahol@gengenp.rug.ac.be

*Both authors contributed equally to this work. tion of feedback responses (Niehaus and Becker 1998; Price 1999). Few conclusive data about defined functions, however, are available.

In Azorhizobium caulinodans ORS571, a microsymbiont of Sesbania rostrata, random mutagenesis gave access to two essential nodulation loci, one for Nod factor synthesis, the other involved in SPS synthesis (Van den Eede et al. 1987). The latter locus, identified by a $\operatorname{Tn} 5$ insertion in the mutant strain ORS571-X15, is involved in the synthesis of activated monosaccharides, precursors for polysaccharide synthesis (Goethals et al. 1994), and corresponds to part of the $r f b$ locus of Salmonella typhimurium. The mutation of ORS571-X15 is located in $o a c 3$, an ortholog of $r f b A$ that encodes a dTDPglucose synthase, which is implied in the synthesis of activated deoxyhexoses (Goethals et al. 1994). oac3 is part of a cluster of four genes (oac0,oacl,oac2, and oac3) that encode enzymes for the synthesis of dTDP-L-rhamnose from glucose1-phosphate (Goethals et al. 1994; W. D'Haeze and M. Holsters, unpublished results). The OAC3 enzyme catalyzes the first step in this pathway (Goethals et al. 1994). The dTDP-L-rhamnose synthase, which presumably catalyzes the last step, is encoded by the oac2 gene. The transcriptional regulation of this region is not yet known. The mutation in the oac3 gene caused a pleiotropic phenotype with rough colony morphology, clumping of bacteria in liquid media, altered $O$ antigen structure, and impaired nodulation. D'Haeze et al. (1998) studied the symbiotic behavior of this mutant in more detail and showed that bacterial invasion was arrested at the stage of intercellular infection pocket formation. The ORS571-X15 bacteria penetrated the host intercellularly through two to three cell layers and formed infection pockets in the outer cortex but could not induce the formation of inner cortical infection pockets and threads (D'Haeze et al. 1998).

To better study the symbiotic functions of azorhizobial surface carbohydrates, we characterized the oac2 gene by creating a nonpolar-directed mutation and compared the mutant phenotype with the oac 3 mutation. Knockout of the rhamnose synthase gene caused a far less dramatic phenotype than that caused by the glucose synthase gene. dTPD-L-rhamnose synthesis seems to be important for a correct buildup of lipopolysaccharide (LPS) and extracellular polysaccharides (EPS), which play an essential role in the establishment of a successful symbiosis. 


\section{RESULTS}

\section{Construction and phenotype of ORS571-oac2.}

To create a nonpolar mutation, the $a p h A-3$ cassette (Ménard et al. 1993) was inserted into a BsmI site located in the $5^{\prime}$ part of the oac2 gene of $A$. caulinodans ORS571 (see below). The mutation was introduced into the ORS571 genome by exchange recombination with the suicide vector pJQ200uc1 (Table 1). For complementation analysis, the plasmid poacMG was constructed harboring oac2 and two upstream open reading frames (W. D'Haeze and M. Holsters, unpublished results) cloned in the wide host-range vector pBBR1MCS-3 (Table 1).

The mutant strain ORS571-oac2 had normal growth behavior, indistinguishable from the wild-type strain on solid and liquid media (data not shown). Electrophoretic analysis of LPS preparations isolated by the hot phenol method (see below) revealed that the LPS from ORS571-oac2 partitioned in the water phase, similarly to the LPS from the mutant ORS571-X15 (Goethals et al. 1994). On the contrary, LPS from wild-type ORS571 and the complemented strain ORS571-oac2(poacMG) partitioned in the phenol phase. The $O$ antigen of ORS571-oac2 LPS was altered and showed a lower degree of polymerization, comparable to the pattern of the ORS571-X15 LPS (Fig. 1, lanes 3 and 5). The band migration pattern of LPS, prepared from ORS571-oac2(poacMG), was similar to that of the wild type (Fig. 1, lanes 2 and 4). Analysis of the sugar composition of LPS preparations from the wild type and ORS571-oac2 showed the presence of 3deoxy-D-manno-2-octulosonic acid (Kdo) and rhamnose in a molar ratio of 1:4.9 and 1:0.2, respectively. Additionally. the ratio of glucose to Kdo was changed in ORS571-oac2: 1:0.2 in the mutant versus 1:3.1 in wild-type ORS571.

The overall hydrophobicity of ORS571, ORS571-oac2, and ORS571-X15 was determined by a hydrocarbon adherence method (see below). ORS571-oac2 was slightly more hydrophobic than ORS571, but ORS571-X15 showed a strongly enhanced hydrophobicity (Fig. 2).
The oac 2 mutation causes arrest of nodule development.

Upon inoculation of $S$. rostrata stems or roots with strain ORS571-oac2, nodule initiation and the early nodulation stages were normal, but further nodule development was arrested, leading to severely defective organs in which no signs of nitrogen fixation could be observed (Fig. 3A). The nodulelike structures were green inside, indicating a significant reduction in the level of functional leghemoglobin (Fig. 3B). Complementation of the mutation by poacMG restored the ability to develop wild-type nodules and fix nitrogen (data not shown). Use of bacteria containing the $\beta$-glucuronidase reporter fused to the nodA promoter region provided the first indication of a lack of bacterial internalization and bacteroid formation in nodule-like structures (Fig. 3C). The plasmid pRG960SD-32 (Van den Eede et al. 1992) was introduced into ORS571 and ORS571-oac2, and approximately 50 stem nodules or nodule-like structures were harvested for each strain 3 weeks after inoculation. Hand-cut sections were stained with 5-bromo-4-chloro-3-indolyl- $\beta$-D-glucuronic acid and observed under a binocular (representative observations are shown in Fig. 3C). A section through nodules induced by ORS571(pRG960SD-32) shows central tissues colonized by bacteria. Remnants of infection pockets and infection threads can be seen in Figure 3C. A section through a defective nodule induced by ORS571-oac2(pRG960SD-32) shows infection centers with infection pockets and infection threads but no central tissue colonization (Fig. 3C).

Semi-thin sections $(2.5 \mu \mathrm{m})$ of 3 -week-old nodules or nodule-like structures were stained with toluidine blue and viewed by bright-field optics (Fig. 4A to D). Wild-type nodules have a central tissue that is surrounded by a differentiated cortex, including an inner cortex made up of a few organized layers of flat cells that function as an $\mathrm{O}_{2}$ diffusion barrier (James et al. 1998) (Fig. 3A). Sections of nodule-like structures induced by ORS571-oac2 showed abnormal tissue organization, without clear demarcation between central and peripheral tissues, specialized inner cortex, or any sign of

Table 1. Bacterial strains and plasmids

\begin{tabular}{|c|c|c|}
\hline Strains/plasmids & Relevant characteristics & Reference \\
\hline \multicolumn{3}{|l|}{ Azorhizobium caulinodans } \\
\hline ORS571 & A. caulinodans wild-type strain $(\mathrm{Cb})^{\mathrm{a}}$ & Dreyfus et al. 1988 \\
\hline ORS571-X15 & ORS571 derivative carrying a Tn 5 insertion in oac $3(\mathrm{Cb}, \mathrm{Km})$ & Goethals et al. 1994 \\
\hline ORS571-oac2 & ORS571 derivative carrying the $a p h A-3$ cassette of pUC18K in $o a c 2(\mathrm{Cb}, \mathrm{Km})$ & This work \\
\hline ORS571-oac2(poacMG) & ORS571-oac2 derivative carrying poacMG $(\mathrm{Cb}, \mathrm{Km}, \mathrm{Tc})$ & This work \\
\hline ORS571(pRG960SD-32) & ORS571 derivative carrying pRG960SD-32 (Cb, Sp, Sm) & Van den Eede et al. 1992 \\
\hline ORS571-oac2(pRG960SD-32) & ORS571-oac2 derivative carrying pRG960SD-32 (Cb, Km, Sp, Sm) & This work \\
\hline \multicolumn{3}{|l|}{ Plasmids } \\
\hline pRK2013 & Helper plasmid used in triparental conjugations $(\mathrm{Km})$ & Ditta et al. 1980 \\
\hline pBBR1MCS-3 & Cloning vector $(\mathrm{Tc})$ & Kovach et al. 1995 \\
\hline pUC19 & Cloning vector $(\mathrm{Cb})$ & Yanisch-Perron et al. 1985 \\
\hline pRG960SD-32 & pRG960SD derivative carrying a nodA-uidA fusion (Sp, Sm) & Van den Eede et al. 1992 \\
\hline pRG290-6 & pRK290 carrying a 6,300-bp EcoRI fragment that contains oac2 (Cb) & Goethals et al. 1994 \\
\hline pUC19-oac3200ES & pUC19 derivative carrying a 3,200-bp EcoRI-StuI fragment of pRG290-6 (Cb) & This work \\
\hline pUC18K & $\begin{array}{l}\text { pUC18 derivative carrying the } a p h A-3 \text { cassette designed to make nonpolar muta- } \\
\text { tions }(\mathrm{Cb})\end{array}$ & Ménard et al. 1993 \\
\hline pUC19-oac3200ES-K & pUC19-oac3200ES derivative carrying the aphA-3 cassette in oac2 $(\mathrm{Cb}, \mathrm{Km})$ & This work \\
\hline pJQ200uc1 & Selectable suicide vector containing sacB of Bacillus subtilis $(\mathrm{Gm})$ & Quandt and Hynes 1993 \\
\hline pJQ-oac2-K & pJQ200uc1 derivative carrying oac 2 with the $a p h A-3$ cassette $(\mathrm{Gm}, \mathrm{Km})$ & This work \\
\hline poacMG & $\begin{array}{l}\text { pBBR1MCS-3 derivative carrying a 2,700-bp EcoRI-PvuII fragment of pUC19- } \\
\text { oac3200ES that contains oaco, oac1, and oac2 (Tc) }\end{array}$ & This work \\
\hline
\end{tabular}


bacterial internalization (Fig. 4B). A comparison of the "mature" central regions clearly showed the aberrant organization of the defective nodules induced by ORS571-oac2, without plant cell invasion and with a huge number of large infection threads (Fig. 4C and D).

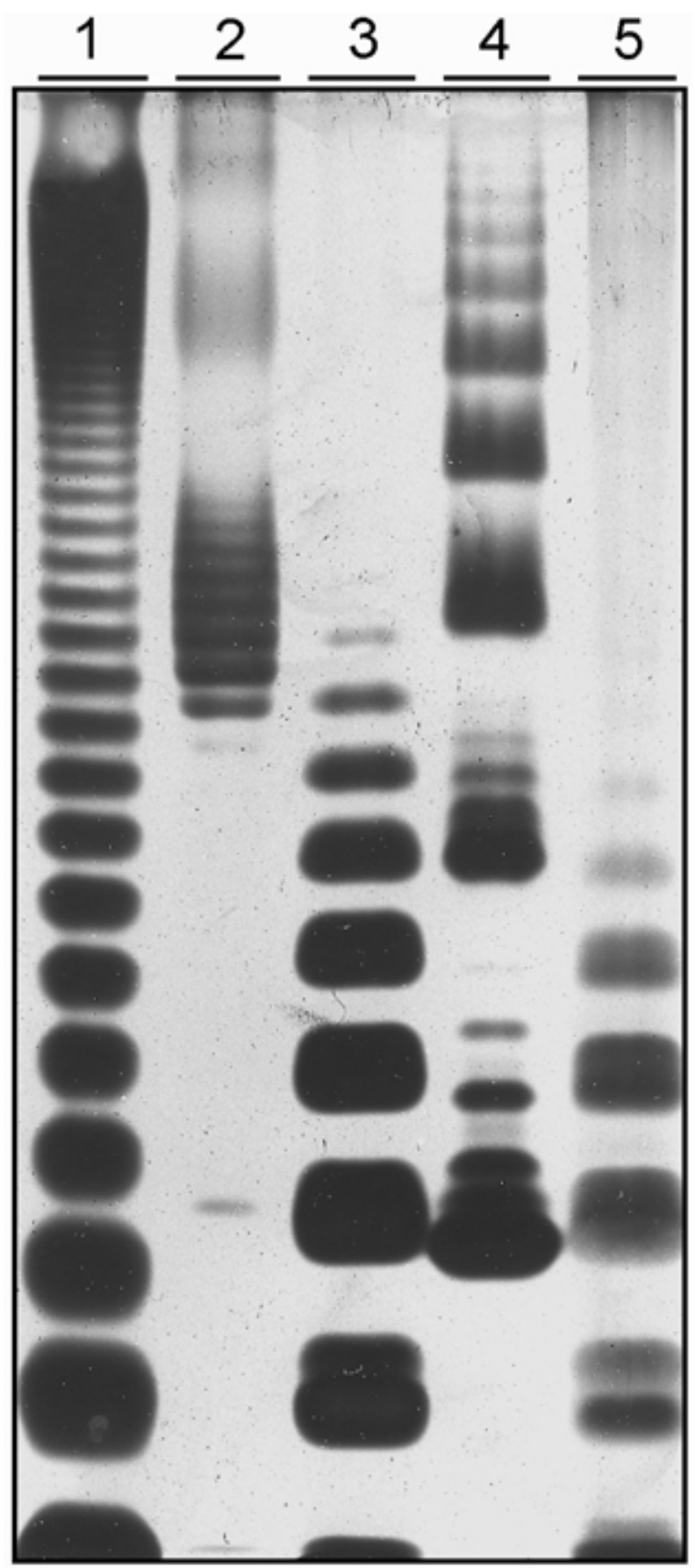

Fig. 1. Deoxycholate-polyacrylamide gel electrophoresis band migration patterns of lipopolysaccharide (LPS). Lane 1: Salmonella typhimurium; lane 2: ORS571; lane 3: ORS571-oac2; lane 4: ORS571oac2(poacMG); lane 5: ORS571-X15. LPS was prepared by the hot water-phenol method. Lanes 2 and 4: phenol phase; lanes 3 and 5: water phase. Gel was silver stained, as described in text. No LPS could be detected with this method in the water phase of ORS571 and ORS571oac2(poacMG) and the phenol phase of ORS571-X15 and ORS571oac2 (Goethals et al. 1994; data not shown).

\section{Nodule penetration by ORS571-oac2 is blocked} at the internalization stage and shows defense symptoms.

Cells adjacent to infection pockets induced by ORS571oac2 were unusually large and their walls emitted a blue fluorescence under UV light, indicative of the presence of phenolic compounds (Fig. 5A and B). This strong autofluorescence had never been observed in the walls of cells adjacent to infection pockets formed by the wild-type strain (Fig. 5C and D).

Electron microscopic observations showed striking differences between infection threads induced by wild-type or mutant bacteria (Fig. 6). Wild-type infection threads harbored few bacteria (Fig. 6A and E), which were embedded in an electron-dense matrix. The plant cells in the invasion zone had a large volume of cytosol and small vacuoles (Fig. 6A). Occasionally, infection thread wall degradation and bacterial internalization events were observed (Fig. 6A and C). In contrast, in nodule-like structures induced by ORS571-oac2, infection threads were wide and harbored many more bacteria that were irregular in shape and showed an electron-dense staining, which could be a sign of death (Fig. 6B, D, and E). Internalization events or internalized bacteria were not seen. The thread walls were extremely thick, consisting of many layers of a fibrous material (Fig. 6E). The plant cells in this tissue had a small volume of cytosol and large vacuoles (Fig. 6B). A higher magnification of an infection thread clearly shows the abnormal thread wall, which was tenfold thicker than in the wild-type nodules (Fig. 6E).

\section{Quantification of SPS produced by ORS571, ORS571-oac2, and ORS571-X15.}

The appearance of bacteria in infection pockets was observed by electron microscopy in an attempt to better understand the difference in the tissue-invasion capacity of ORS571-X15, which can only form infection pockets (D'Haeze et al. 1998), and ORS571-oac2, which can form infection pockets and threads (Fig. 6). Sections were made through a 4-day-old developing nodule and nodule-like structure induced by ORS571 and ORS571-oac2, respectively, and through a 7-day-old pseudonodule induced by ORS571-X15; similar infection pocket regions were studied. Wild-type bacteria were surrounded completely by a thick layer of low electron-dense material, suggesting the presence of a massive amount of what was most likely EPS (Fig. 7A and B). A similar layer also was present around ORS571-oac2, but in a lesser

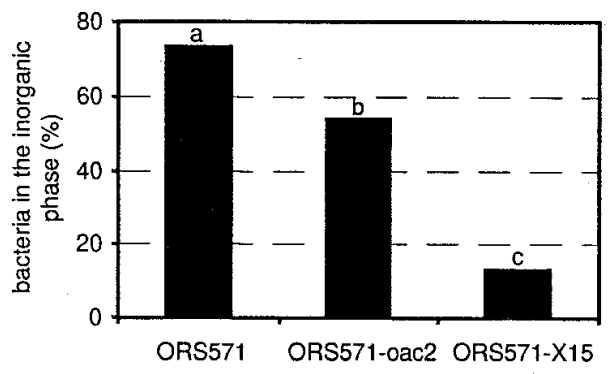

Fig. 2. Hydrophobicity of ORS571, ORS571-oac2, and ORS571-X15. The hydrophobicity is expressed as the percentage of bacteria that remained in the inorganic phase after mixing with octane. The average of eight independent experiments is presented. Values that are significantly different $(p<0.05)$ are indicated by a, b, or $\mathrm{c}$. 
amount (Fig. 7C and D), in contrast to ORS571-X15, where it could never be detected (Fig. 7E and F).

In order to quantify EPS production, ORS571, ORS571oac2, and ORS571-X15 were cultivated on plates containing MMO medium or LSO medium, with or without ammonium (see below). EPS were quantified by the anthrone method (Glucksmann et al. 1993; Reed et al. 1991). The results (Fig. 8) demonstrate that i) ORS571 produces a huge amount of EPS when grown on LSO medium, in contrast to cultivation on media supplied with ammonium; ii) ORS571-oac2 produced more EPS on LSO medium than ORS571-X15, but approximately four to five times less than the wild-type strain; and iii) the presence of naringenin does not have a major influence on the production of EPS (Fig. 8). The sugar content of EPS prepared from ORS571, which was grown on LSO medium, was analyzed (see below). The high-pressure liquid chromatography (HPLC) data consisted of three peaks that eluted at 20.51, 23.39, and $25.64 \mathrm{~min}$, in a relative ratio of 1:58:1.5, respectively (data not shown). Glucose, galactose, and arabinose-fucose standards were eluted at 20.30, 23.10, and $25.27 \mathrm{~min}$, respectively.

\section{DISCUSSION}

The oac2 gene of A. caulinodans is part of a cluster of four genes corresponding to the $r f b$ locus of $S$. typhimurium. Previously, we characterized $o a c 3$, an $r f b A$ ortholog, encoding a dTDP-L-glucose synthase (Goethals et al. 1994). dTDP-Lglucose is a precursor for dTDP-L-rhamnose synthesis. The OAC2 enzyme is a dTDP-L-rhamnose synthase that supposedly catalyzes the last step of this pathway. The knockout of oac3 had dramatic consequences, causing a pleiotropic phenotype (Goethals et al. 1994). The LPS were affected, but most likely other SPS were altered as well (see below). During its interaction with the host plant, the oac3 mutant ORS571-X15 was arrested in outer cortical infection pockets, the primary colonization sites during the invasion process (D'Haeze et al. 1998).

The data on the consequences of an oac2 knockout throw light on the role in symbiosis of the synthesis of dTPD-Lrhamnose for the production of LPS and EPS in A. caulinodans. With use of the hot water-phenol method, LPS from ORS571-oac2 and ORS571-X15 partitioned in the water phase and therefore had different physicochemical properties than the LPS of the wild-type strain and complemented mutants (Goethals et al. 1994; this work) that partitioned in the phenol phase. Sodium dodecyl sulfate-polyacrylamide gel electrophoresis analysis and silver staining, which are considered suitable tools for an initial characterization of LPS (Forsberg and Carlson 1998; Hitchcock and Brown 1983), showed that the band migration patterns of LPS from the oac2 and the oac 3 mutants were similar to each other and differed from the patterns of the wild type and the complemented mutant by a shift toward lower molecular weight. The presumed function of the oac2 gene was supported by the presence of reduced rhamnose-Kdo levels in the LPS fraction of ORS571oac2. Rhamnose incorporation in the $O$ antigen of LPS synthesized by Rhizobium sp. CFN42 (Kannenberg and Brewin 1994) and $R$. trifolii 4s (Wang and Hollingsworth 1994) has been observed. In a variety of bacteria such as $S$. typhimurium strain LT2 (Jiang et al. 1991), Yersinia enterocolitica serotype O:3 (Zhang et al. 1993), and S. enterica (Xiang et al. 1993), the $r f b A B C D$ genes have been demonstrated to be involved in the synthesis of dTDP-rhamnose that is used to synthesize the $O$ antigen. The same feature may be true for $A$. caulinodans ORS571 because ORS571-oac2 produced truncated LPS

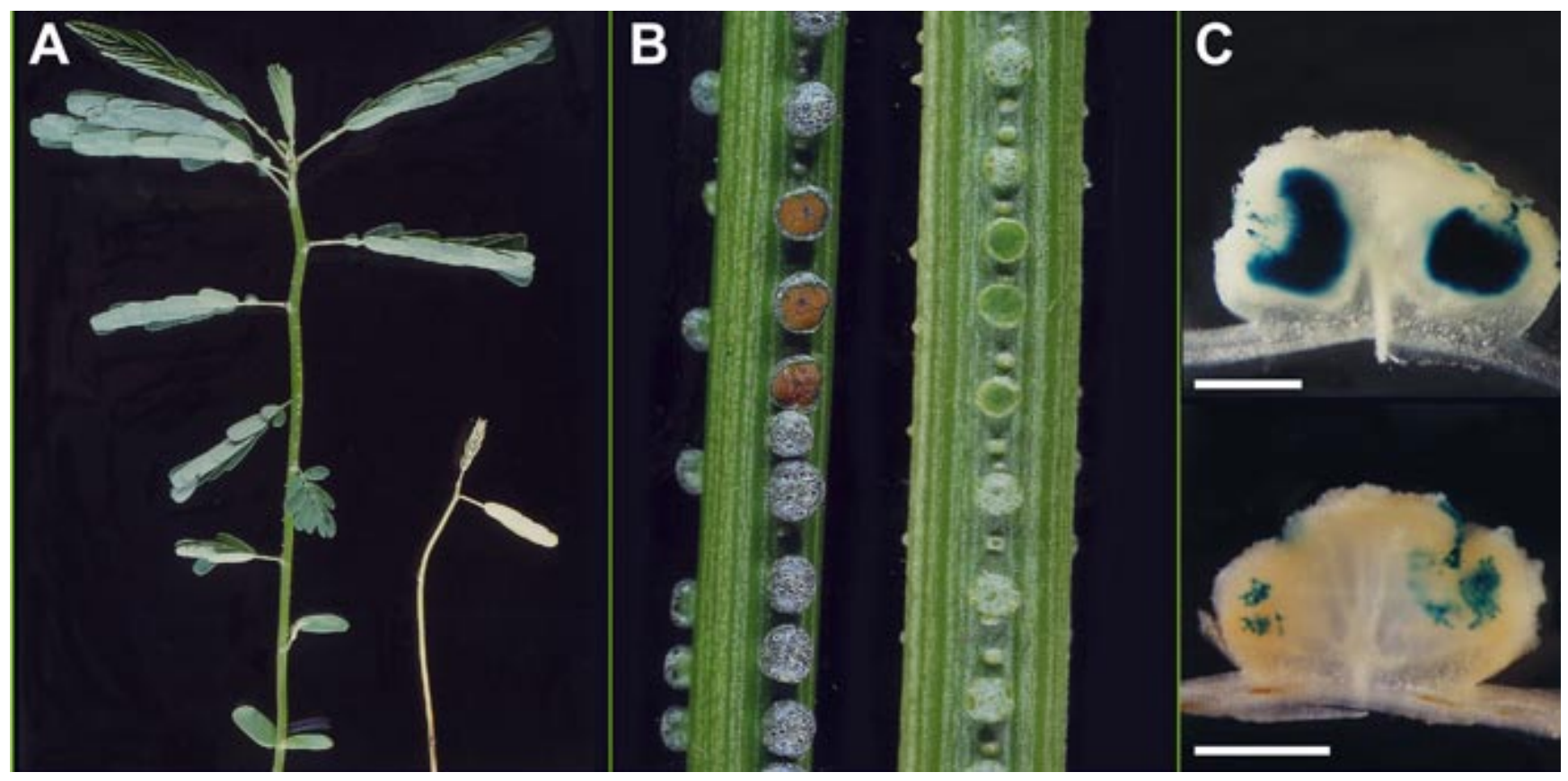

Fig. 3. Stem nodulation by wild-type ORS571 and ORS571-oac2 mutant. A, Sesbania rostrata plants, the roots of which were inoculated with ORS571 (left) and ORS571-oac2 (right), were photographed 3 weeks after inoculation. B, Stems inoculated with ORS571 (left) and ORS571-oac2 (right). Nodules were cut by hand 20 days after inoculation. Orange-brown is the characteristic color for leghemoglobin. C, GUS-stained, hand-cut sections of 3week-old nodules induced by ORS571(pRG960SD-32) (top) and ORS571-oac2(pRG960SD-32) (bottom). Bars = $1 \mathrm{~mm}$. 
molecules, on the basis of faster migration in detergent gel electrophoresis. The rhamnose levels of LPS from ORS571oac2 were reduced, although not to zero, indicating that yet another rhamnose synthase is present in A. caulinodans. Two pathways for rhamnose synthesis occur in some Salmonella spp. serovars (Schnaitman and Klena 1993).

Rhamnose also is a component of a nodule polysaccharide produced by Bradyrhizobium japonicum (An et al. 1995) and has been found in the EPS of some Bradyrhizobium spp. strains (Niehaus and Becker 1998). During growth in infection pockets, ORS571 produced a thick, low, electron-dense layer, consisting presumably of EPS. ORS571-oac2 was surrounded by a much thinner layer of low, electron-dense material, which could be either capsular polysaccharides (CPS) or a truncated form of EPS, whereas ORS571-X15 bacteria were completely bare. This observation suggests that wild-type EPS may contain glucose and rhamnose. Conditions were obtained, under which EPS production could be quantified and characterized. Free-living, wild-type bacteria produced massive amounts of EPS when cultivated on LSO medium. ORS571-oac2 and ORS571-X15 produced fivefold and tenfold less EPS than ORS571, respectively. Sugar determination of wild-type EPS revealed two minor and one major products with elution times corresponding to those of glucose, arabinose-fucose, and galactose, respectively. The major product is most likely a glu- cose derivative rather than a galactose, as suggested by preliminary cellulose thin-layer chromatography analyses (W. D'Haeze and M. Holsters, unpublished results). Unexpectedly, no rhamnose could be detected. More likely, rhamnose was converted into another compound, although it cannot be excluded that the free-living conditions did not resemble exactly the in situ conditions, thereby affecting the synthesis of rhamnose, or that the method used was not sensitive enough to detect rhamnose in these samples. It is obvious that a more thorough characterization of EPS is required in a follow-up study.

In hydrophobicity assays in which EPS is washed away, wild type and oac 2 behaved similarly, although their LPS are very different, thus suggesting a third actor in the play, possibly CPS, which could be responsible for the thin slime layer surrounding ORS571-oac2 in infection pockets. In ORS571-X15, all SPS molecules containing either rhamnose or glucose derivatives are absent, and the result is an arrest in the outer cortex. The formation of outer cortical infection pockets is a process that depends on Nod factors (D'Haeze et al. 1998). The CPS of A. caulinodans may be required for the release from outer infection pockets and the formation of infection threads, whereas EPS-LPS may be important for the release from infection threads and the subsequent internalization into plant cells. Additionally, LPS and CPS produced by ORS571, ORS571-oac2, and ORS571-
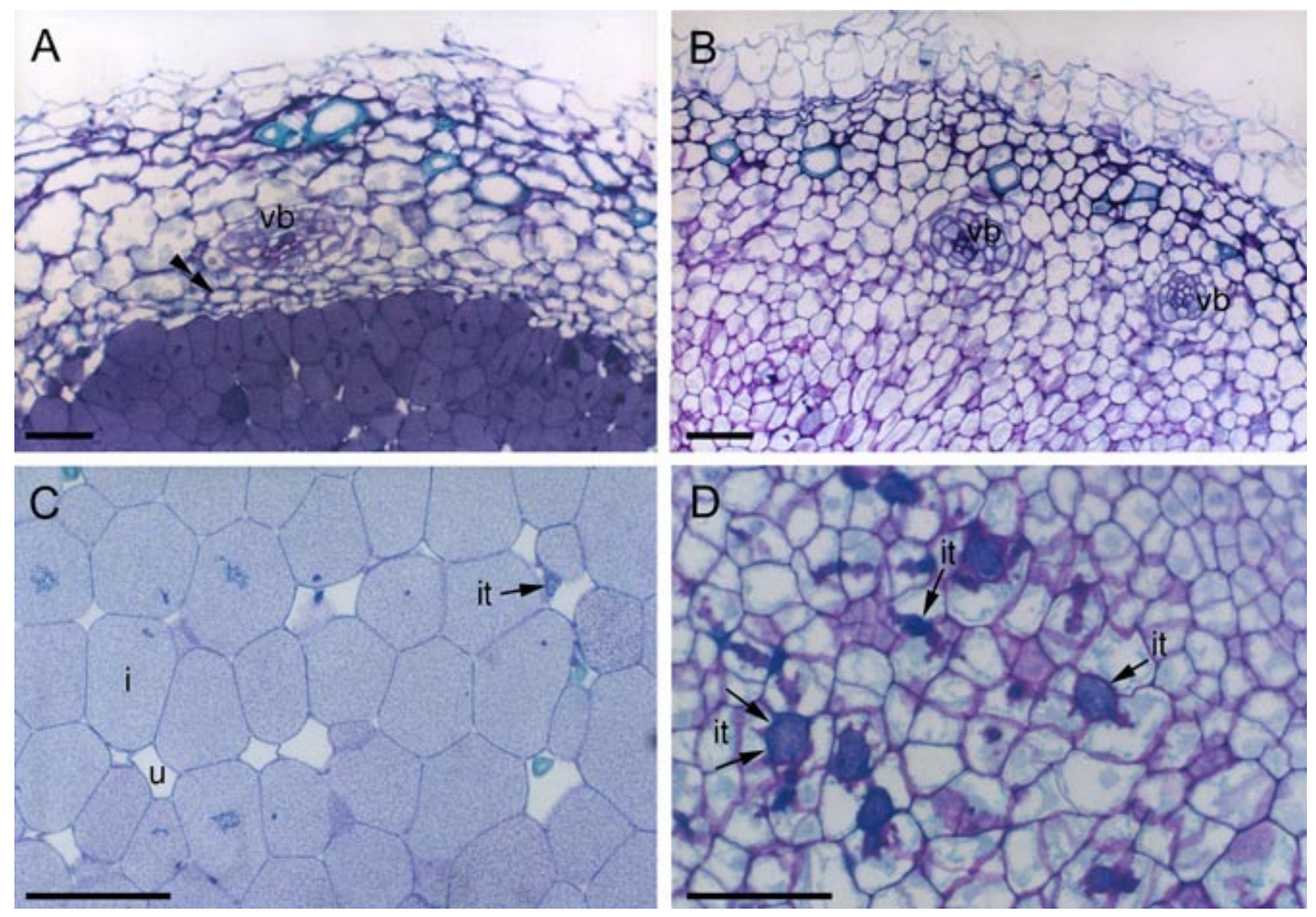

Fig. 4. Morphology of nodules and nodule-like structures. Light micrographs of longitudinal sections through $\mathbf{A}$ and $\mathbf{B}$, peripheral and $\mathbf{C}$ and $\mathbf{D}$, central regions of $\mathbf{A}$ and $\mathbf{C}$, wild-type stem nodules and $\mathbf{B}$ and $\mathbf{D}$, nodule-like structures induced by ORS571-oac2. Double arrowhead indicates flattened inner cortex cells. $\mathrm{i}=$ infected cell; it $=$ infection thread; $\mathrm{u}=$ uninfected cell; $\mathrm{vb}=$ vascular bundle. Bars $=50 \mu \mathrm{m}$. 
X15 will be purified and characterized in a follow-up study in order to better correlate differences in infection behavior with differences in cell envelope properties.

The invasion of ORS571-oac2 was accompanied by strong symptoms of defense at the level of infection threads and surrounding plant cells such as thick walls, autofluorescence, and possibly loss of bacterial viability. Somewhat similar observations have been made in root nodules of Medicago truncatula (Niehaus et al. 1998), which were induced by the Sinorhizobium meliloti LPS mutant Rm6963 and in pea nodules by Rhizobium leguminosarum LPS mutant 3841 (Perotto et al. 1994). In those systems, however, internalization of bacteria did take place, whereas in the interaction between ORS571oac2 and $S$. rostrata, bacterial exit from infection threads was blocked completely. It seems logical to presume that the arrested nodule development is the consequence of arrested bacterial invasion and the elicitation of defense responses. Perhaps nodule development stops because a conditional effect of the oac2 mutation is lethal for the bacterial viability in infection threads, which is caused by a lack of suppression of defense, or because the truncated SPS induce a defense reaction. Finally, it is possible that LPS or EPS are active signaling molecules for the release of bacteria from infection threads. Indeed, Verma and Hong (1996) proposed that a group of rhizobial signal molecules, other than Nod factors, may trigger endocytosis. These molecules were defined as "endocytosis factors" (Verma and Hong 1996).

Hence, the oac2 knockout renders the interaction between A. caulinodans and $S$. rostrata incompatible at the bacterial internalization stage. The molecular mechanisms that mediate the switch from a compatible to an incompatible interaction remain to be described, but a controlling role of rhamnosecontaining LPS and EPS is extremely probable.
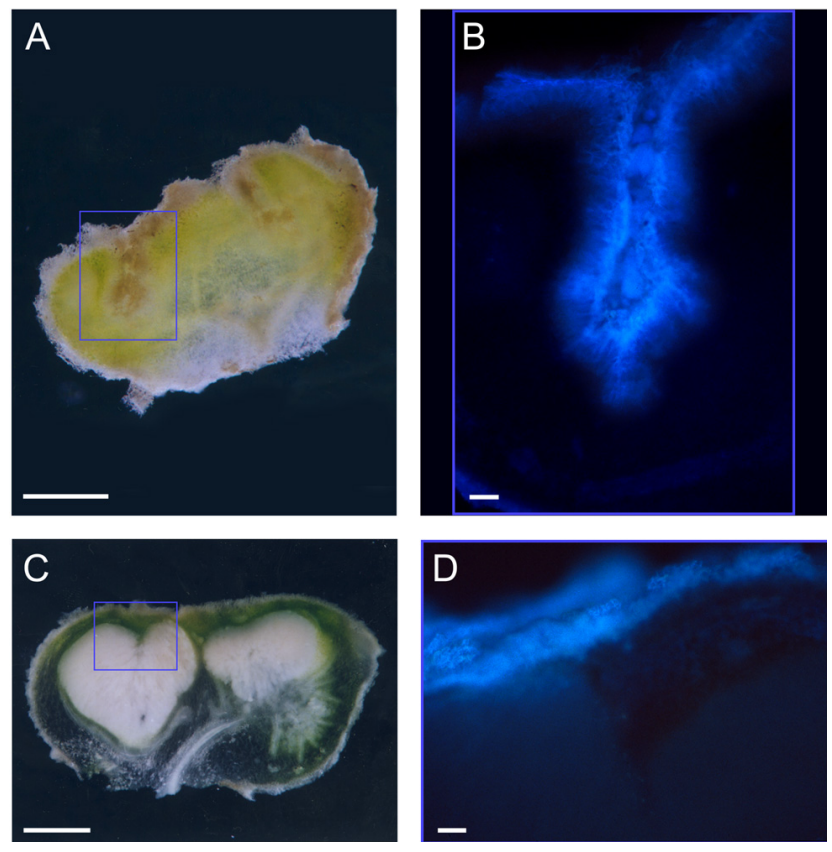

Fig. 5. Epifluorescent micrographs of nodules and nodule-like structures. Infection threads viewed by normal (left) and fluorescence (right) microscopy in A and B, 3-week-old nodule-like structure induced by ORS571-oac2 and in $\mathbf{C}$ and D, nodules induced by ORS571. Bars = 1 $\mathrm{mm}(\mathbf{A}$ and $\mathbf{C})$ and $100 \mu \mathrm{m}(\mathbf{B}$ and $\mathbf{D})$.

\section{MATERIALS AND METHODS}

\section{Bacterial strains and plasmids.}

Bacterial strains and plasmids are listed in Table 1. Escherichia coli strains were grown in Luria-Bertani medium (Miller 1972). A. caulinodans ORS571 strains were grown on either YEB (Geremia et al. 1994), MMO (Goethals et al. $1989)$, or LSO medium, with or without $0.1 \%\left(\mathrm{NH}_{4}\right)_{2} \mathrm{SO}_{4}$ (Elmerich et al. 1982). If applicable, naringenin was added at a final concentration of $20 \mu \mathrm{M}$. Antibiotics were added as described by D'Haeze et al. (1998).

\section{Molecular biology techniques.}

Standard molecular techniques were performed as described by Sambrook et al. (1989). To construct the nonpolar mutant ORS571-oac2, a filled-in, 850-bp EcoRI-HincII fragment from plasmid pUC18K (Ménard et al. 1993) containing the kanamycin resistance gene cassette $(a p h A-3)$ was inserted into a T4 DNA polymerase-treated BsmI site of oac2 in plasmid pUC19-oac3200ES, yielding pUC19-oac3200ES-K (Table 1). In this construct, the ATG start codon, located downstream from the kanamycin resistance gene, is in-frame with the TAA stop codon of the oac 2 gene, as confirmed by sequencing.

A filled-in, 4,195-bp EcoRI-HindIII fragment from pUC19oac 3200 ES-K containing the mutated oac 2 gene was cloned in the SmaI site of the suicide vector pJQ200uc1 (Quandt and Hynes 1993). The resulting plasmid was mobilized into the wild-type strain ORS571 by triparental mating (Van den Eede et al. 1992). Cointegrates were identified by selection for gentamicin $(\mathrm{Gm})$ resistance and screening for sensitivity to $15 \%$ (wt/vol) sucrose, both markers of pJQ200uc1. Candidate double recombinants were selected from cointegrates by growth in the presence of $15 \%$ sucrose and kanamycin and subsequent screening for Gm sensitivity. The ORS571-oac2 mutant was confirmed by DNA gel blot analysis. To construct a complementing plasmid, poacMG, a 2.7-kb EcoRI-PvuII fragment containing oac2, was isolated from the plasmid pUC19oac3200ES and cloned in the wide host-range vector pBBR1MCS-3 (Table 1).

\section{LPS preparation and analysis.}

Bacteria were grown in YEB medium until stationary phase and harvested by centrifugation. LPS was extracted from the bacterial pellets by the hot-water method (Goethals et al. 1994). The water phases were washed additionally with phenol to remove traces of phenol-soluble material. Water and phenol phases were dialyzed (molecular weight cut off at 12,000 to 14,000; Spectra/Por, Spectrum, Laguna Hill, CA, U.S.A.), and treated with $20 \mu \mathrm{g}$ of proteinase $\mathrm{K}$ per $\mathrm{ml}$ at $37^{\circ} \mathrm{C}$ overnight. The samples were dialyzed overnight against distilled water and concentrated in vacuo. Prior to electrophoresis on a $12.5 \%$ polyacrylamide gel with deoxycholate as detergent (Carlson et al. 1995), LPS fractions were ultracentrifuged at $100,000 \mathrm{~g}$ for $4 \mathrm{~h}$. The LPS pellet was resuspended in water, and gels were silver stained to detect LPS (Tsai and Frasch 1982). LPS from S. typhimurium was used as control (SigmaAldrich, St. Louis, MO, U.S.A). To check for the presence of other Kdo-rich polymers, LPS preparations were electrophoresed, and the gel was silver stained after treatment with Alcian blue (Reuhs et al. 1993). No evidence for the presence of other major Kdo polymers was obtained (data not shown). 
To determine monosaccharides, LPS were hydrolyzed in $1 \%$ acetic acid at $100^{\circ} \mathrm{C}$ for $90 \mathrm{~min}$, cooled to room temperature, and centrifuged $(1000 \times g)$ for 5 min to remove lipid A (Dazzo et al. 1991). The supernatant was washed, and lipid-free polysaccharides were dried and hydrolyzed to monosaccharides, according to Stevenson et al. (1994). Monosaccharides were converted to their corresponding trimethylsilylethers of methyl glycosides and analyzed by gas chromatography-mass spectrometry, as described (Wolucka and de Hoffmann 1995). Glucose and rhamnose were identified by their retention times and
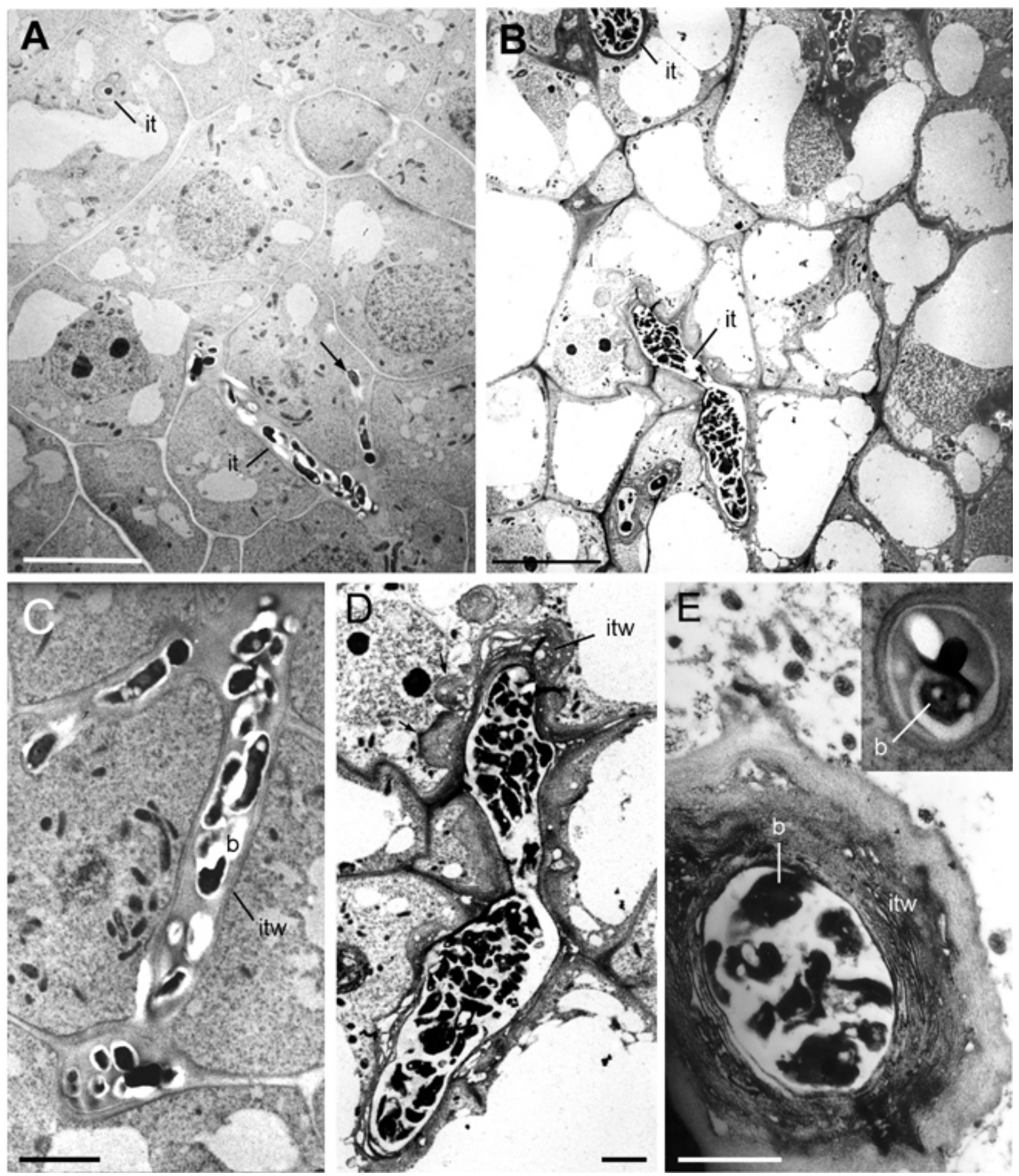

Fig. 6. Electron micrographs of central tissues and infection threads in stem nodule and nodule-like structures induced by ORS571 and ORS571-oac2, respectively. A, Wild-type central tissue. Arrow indicates a bacterium releasing from an infection thread. B, Central tissue of a nodule-like structure induced by ORS571-oac2. C, Enlargement of A, showing rod-shaped bacteria in infection threads. D, Enlargement of B, showing aberrantly shaped bacteria. E, Closeup of the wall of abnormal threads in ORS571-oac2-induced nodule-like structures (inset: wild-type infection thread wall for comparison $) . \mathrm{b}=$ bacteria; it $=$ infection thread; itw = infection thread wall. Bars $=10 \mu \mathrm{m}(\mathbf{A}$ and $\mathbf{B})$ and $2 \mu \mathrm{m}(\mathbf{C}-\mathbf{E})$. 
mass spectrometry spectra. Kdo was quantified by a colorimetric method (Strominger et al. 1959).

\section{Hydrophobicity assay.}

Bacteria were grown in MMO medium until early stationary phase. The hydrophobicity was determined as described previously (Goethals et al. 1994). A statistical analysis was performed with use of the Student's $t$ test.

\section{Quantification and sugar analysis of EPS.}

EPS were quantified by the anthrone method. Briefly, bacteria were grown on plates for 3 to 4 days to avoid contaminations of sugars in liquid media. Bacteria with EPS were removed from the plate, transferred to a recipient, resuspended in $300 \mu \mathrm{l}$ of $\lambda$ buffer $\left(10 \mathrm{mM}\right.$ Tris- $\mathrm{HCl} ; 10 \mathrm{mM} \mathrm{MgSO}_{4}, \mathrm{pH}$ 7.2), and centrifuged for $5 \mathrm{~min}$ at 14,000 rpm. The supernatant was put aside, and the pellet was washed with an additional $300 \mu \mathrm{l}$ of $\lambda$ buffer, centrifuged again, and added to the first supernatant. The bacterial pellet was resuspended in $500 \mu \mathrm{l}$ of

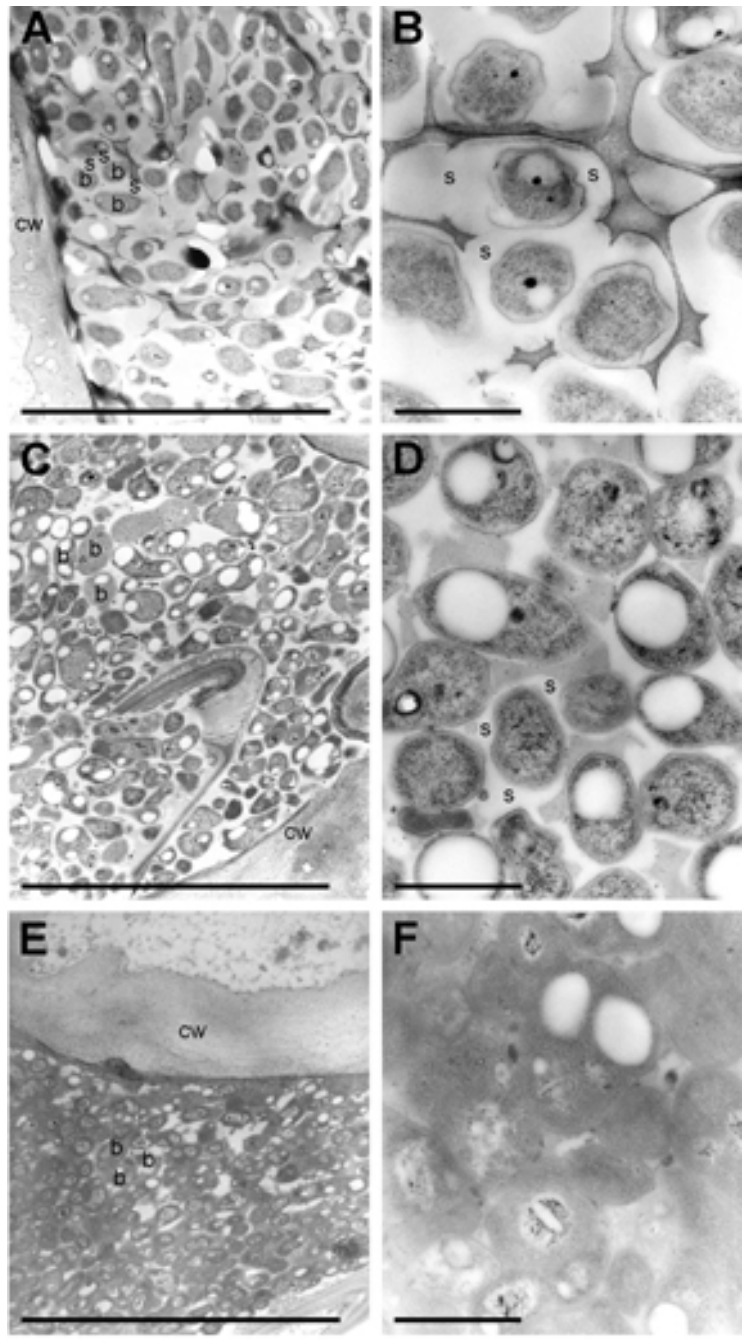

Fig. 7. Electron micrographs of infection pockets in A and B, a 4-dayold developing nodule induced by ORS571, C and D, a 4-day-old nodule-like structure induced by ORS571-oac2, and E and F, a 7-day-old pseudonodule induced by ORS571-X15. b = bacteria; $\mathrm{cw}=$ thickened cell wall of a neighboring cell; $\mathrm{s}=$ extracellular polysaccharides. Bars = $10 \mu \mathrm{m}(\mathbf{A}, \mathbf{C}$, and $\mathbf{E})$ and $1 \mu \mathrm{m}(\mathbf{B}, \mathbf{D}$, and $\mathbf{F})$. $\lambda$ buffer to measure the optical density (OD) at $600 \mathrm{~nm}$. Of the combined supernatant, 50 to $300 \mu \mathrm{l}$ were diluted with distilled water to a final volume of $500 \mu$ l. One milliliter of $0.2 \%$ anthrone (Sigma-Aldrich) in concentrated $\mathrm{H}_{2} \mathrm{SO}_{4}$ was then added carefully, and the mixture was vortexed for $15 \mathrm{~s}$. Subsequently, the $\mathrm{OD}_{620}$ was measured. D-glucose was used as a standard to calculate the glucose equivalents in the EPS samples, which were divided by the respective $\mathrm{OD}_{600}$ in order to normalize influences of different bacterial densities.

EPS samples were hydrolyzed in $2 \mathrm{M}$ trifluoroacetic acid at $121^{\circ} \mathrm{C}$ for $2 \mathrm{~h}$. The sugar analysis was performed as described by Honda et al. (1989). Briefly, approximately $20 \mu \mathrm{g}$ of glucose equivalents were taken and mixed with $50 \mu \mathrm{l}$ of $0.5 \mathrm{M}$ methanolic solution of 3-methyl-1-phenyl-2-pyrazolin-5-on (Sigma-Aldrich) and $50 \mu \mathrm{l}$ of $0.3 \mathrm{M} \mathrm{NaOH}$. This mixture was incubated at $70^{\circ} \mathrm{C}$ for $30 \mathrm{~min}$, cooled, and neutralized with $150 \mu \mathrm{l}$ of $0.1 \mathrm{M} \mathrm{HCl}$. The solution was evaporated until dry. The pellet was resuspended in $200 \mu \mathrm{l}$ of water and $200 \mu \mathrm{l}$ of chloroform, and the mixture was shaken vigorously and centrifuged for $5 \mathrm{~min}$ at $14,000 \mathrm{rpm}$. The water phase was dried, and the pellet was resuspended in $100 \mu \mathrm{l}$ of $18 \%$ acetonitrile in $0.1 \mathrm{M}$ phosphate buffer ( $\mathrm{pH} 7.0)$. A fraction was analyzed by HPLC (Honda et al. 1989).

\section{Nodulation assays.}

S. rostrata seeds were surface sterilized and germinated (Goormachtig et al. 1995). For root nodulation assays, 2-dayold seedlings were transferred to tubes as described (Fernández-López et al. 1998). For stem nodulation assays, plants were grown in pots. Stems were inoculated by painting with a bacterial suspension. Plants were cultured at $28^{\circ} \mathrm{C}$, with a light period of $16 \mathrm{~h}$. Reisolation of ORS571-oac2 from stem nodules was performed as described by D'Haeze et al. (1998).

\section{GUS staining of stem nodule sections.}

Nodules induced by ORS571 derivatives carrying the nodA-uidA reporter plasmid were harvested 3 weeks after inoculation. Hand-cut sections were washed with $90 \%$ acetone and GUS stained, according to D'Haeze et al. (1998), with

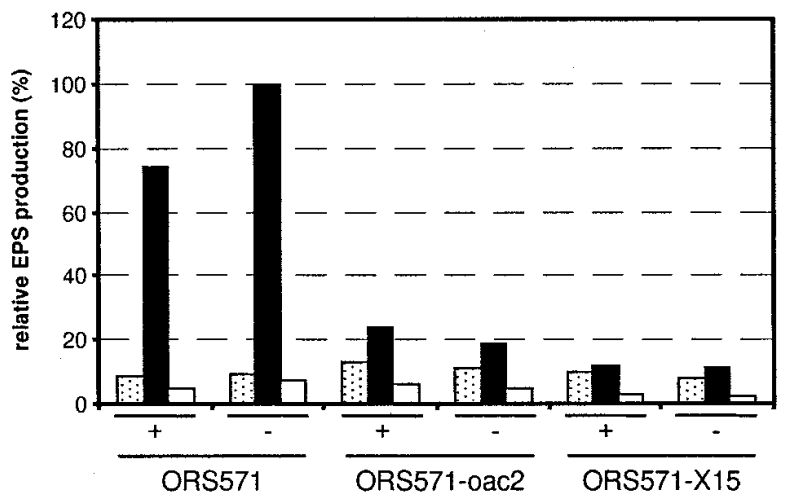

Fig. 8. Extracellular polysaccharides (EPS) quantification. ORS571, ORS571-oac2, and ORS571-X15 were cultivated on MMO medium (dotted bars) and nitrogen fixation medium without ammonium (black bars) or with $0.1 \%\left(\mathrm{NH}_{4}\right)_{2} \mathrm{SO}_{4}$ (white bars) in the presence (+) or absence (-) of naringenin. The equivalent mass of EPS per optical density at $600 \mathrm{~nm}$ for ORS571 grown on nitrogen fixation medium in the absence of naringenin was set at $100 \%$. An average of two independent quantifications is presented. 
$0.5 \mathrm{mg}$ of 5-bromo-4-chloro-3-indolyl- $\beta$-D-glucuronide per $\mathrm{ml}$. Stained sections were observed with a binocular (Zeiss, Jena, Germany).

\section{Microscopy.}

Nodules harvested 4 days and 3 weeks after inoculation were treated for light and electron microscopy, as described by D'Haeze et al. (1998). Nodules for light microscopy were fixed by $2.5 \%$ glutaraldehyde, embedded in Technovit 7100 (Kulzer Histo-Technik, Wehrheim, Germany), and cut into $2.5-\mu \mathrm{m}$ sections. The sections were stained with $0.5 \%$ toluidine blue, mounted with Depex (Sigma-Aldrich), and examined under the bright field of a Diaplan microscope (Leitz, Wetzlar, Germany). Nodules for electron microscopy were fixed by a mixture of $2.5 \%$ formaldehyde and $2.5 \%$ glutaraldehyde in $0.1 \mathrm{M}$ sodium-cacodylate buffer, dehydrated, and embedded in LR White hard grade (London Resin, Basingstoke, U.K.). Sections of $2 \mu \mathrm{m}$ were viewed by phase contrast with a light microscope. Once infection threads were located, thin sections of $60 \mathrm{~nm}$ were cut, stained with $2 \%$ uranyl acetate for $12 \mathrm{~min}$ followed by $1 \%$ lead citrate for $5 \mathrm{~min}$, and then examined by transmission electron microscopy (Elmiskop 101; Siemens, Karlsruhe, Germany). For fluorescence microscopy an Axioskop microscope (Zeiss) was used. The blue autofluorescence was observed under UV light.

\section{ACKNOWLEDGMENTS}

We are grateful to R. Rozenberg and E. de Hoffmann (Department of Chemistry, University of Louvain-la-Neuve, Belgium) for the opportunity to perform GC-MS and to help interpret the data; C. Verplancke for growing Sesbania rostrata plants; F. Van Gijsegem for providing pUC18K and for critical reading of the manuscript; M. De Cock for help in preparing the manuscript; and K. Spruyt, R. Verbanck, and S. Debruyne for photographs and artwork.

\section{LITERATURE CITED}

An, J., Carlson, R. W., Glushka, J., and Streeter, J. G. 1995. The structure of a novel polysaccharide produced by Bradyrhizobium species within soybean nodules. Carbohydr. Res. 269:303-317.

Carlson, R. W., Reuhs, B., Chen, T.-B., Bhat, U. R., and Noel, K. D. 1995. Lipopolysaccharide core structures in Rhizobium etli and mutants deficient in $O$-antigen. J. Biol. Chem. 270:11783-11788.

D’Haeze, W., Gao, M., De Rycke, R., Van Montagu, M., Engler, G., and Holsters, M. 1998. Roles for azorhizobial Nod factors and surface polysaccharides in intercellular invasion and nodule penetration, respectively. Mol. Plant-Microbe Interact. 11:999-1008.

Dazzo, F. B., Truchet, G. L., Hollingsworth, R. I., Hrabak, E. M., Pankratz, H. S., Philip-Hollingsworth, S., Salzwedel, J. L., Chapman, K., Appenzeller, L., Squartini, A., Gerhold, D., and Orgambide, G. 1991. Rhizobium lipopolysaccharide modulates infection thread development in white clover root hairs. J. Bacteriol. 173:5371-5384.

Ditta, G., Stanfield, S., Corbin, D., and Helinski, D. R. 1980. Broad host range DNA cloning system for Gram-negative bacteria: Construction of a gene bank of Rhizobium meliloti. Proc. Natl. Acad. Sci. USA 77:7347-7351.

Dreyfus, B., Garcia, J. L., and Gillis, M. 1988. Characterization of Azorhizobium caulinodans gen. nov., sp. nov., a stem-nodulating nitrogen-fixing bacterium isolated from Sesbania rostrata. Int. J. Syst. Bacteriol. 38:89-98.

Elmerich, C., Dreyfus, B. L., Reysset, G., and Aubert, J.-P. 1982. Genetic analysis of nitrogen fixation in a tropical fast-growing Rhizobium. EMBO J. 1:499-503.

Fernández-López, M., Goormachtig, S., Gao, M., D’Haeze, W., Van Montagu, M., and Holsters, M. 1998. Ethylene-mediated phenotypic plasticity in root nodule development on Sesbania rostrata. Proc.
Natl. Acad. Sci. USA 95:12724-12728.

Forsberg, L. S., and Carlson, R. W. 1998. The structures of the lipopolysaccharides from Rhizobium etli strains CE358 and CE359. The complete structure of the core region of $R$. etli lipopolysaccharides. J. Biol. Chem. 273:2747-2757.

Geremia, R. A., Mergaert, P., Geelen, D., Van Montagu, M., and Holsters, M. 1994. The NodC protein of Azorhizobium caulinodans is an $N$-acetylglucosaminyltransferase. Proc. Natl. Acad. Sci. USA 91:2669-2673.

Glucksmann, M. A., Reuber, T. L., and Walker, G. C. 1993. Family of glycosyl transferases needed for the synthesis of succinoglycan by Rhizobium meliloti. J. Bacteriol. 175:7033-7044.

Goethals, K., Gao, M., Tomekpe, K., Van Montagu, M., and Holsters, M. 1989. Common nodABC genes in Nod locus 1 of Azorhizobium caulinodans: Nucleotide sequence and plant-inducible expression. Mol. Gen. Genet. 219:289-298.

Goethals, K., Leyman, B., Van den Eede, G., Van Montagu, M., and Holsters, M. 1994. An Azorhizobium caulinodans ORS571 locus involved in lipopolysaccharide production and nodule formation on Sesbania rostrata stems and roots. J. Bacteriol. 176:92-99.

Goormachtig, S., Valerio-Lepiniec, M., Szczyglowski, K., Van Montagu, M., Holsters, M., and De Bruijn, F. J. 1995. Use of differential display to identify novel Sesbania rostrata genes enhanced by Azorhizobium caulinodans infection. Mol. Plant-Microbe Interact. 8:816-824.

Hitchcock, P. J., and Brown, T. M. 1983. Morphological heterogeneity among Salmonella lipopolysaccharide chemotypes in silver-stained polyacrylamide gels. J. Bacteriol. 154:269-277.

Honda, S., Akao, E., Suzuki, S., Okuda, M., Kakehi, K., and Nakamura, J. 1989. High-performance liquid chromatography of reducing carbohydrates as strongly ultraviolet-absorbing and electrochemically sensitive 1-phenyl-3-methyl-5-pyrazolone derivatives. Anal. Biochem. 180:351-357.

James, E. K., Minchin, F. R., Oxborough, K., Cookson, A., Baker, N. R., Witty, J. F., Crawford, R. M. M., and Sprent, J. I. 1998. Photosynthetic oxygen evolution within Sesbania rostrata stem nodules. Plant J. 13:29-38.

Jiang, X.-M., Neal, B., Santiago, F., Lee, S. J., Romana, L. K., and Reeves, P. R. 1991. Structure and sequence of the $r f b$ (O antigen) gene cluster of Salmonella serovar typhimurium (strain LT2). Mol. Microbiol. 5:695-713.

Kannenberg, E. L., and Brewin, N. J. 1994. Host-plant invasion by Rhizobium: The role of cell-surface components. Trends Microbiol. 2:277-283

Kovach, M. E., Elzer, P. H., Hill, D. S., Robertson, G. T., Farris, M. A., Roop, R. M., II, and Peterson, K. M. 1995. Four new derivatives of the broad-host-range cloning vector pBBR1MCS, carrying different antibiotic-resistance cassettes. Gene 166:175-176.

Ménard, R., Sansonetti, P. J., and Parsot, C. 1993. Nonpolar mutagenesis of the ipa genes defines IpaB, IpaC, and IpaD as effectors of Shigella flexneri entry into epithelial cells. J. Bacteriol. 175:5899-5906.

Miller, J. H. 1972. Experiments in Molecular Genetics. Cold Spring Harbor Laboratory, Cold Spring Harbor, NY, U.S.A.

Niehaus, K., and Becker, A. 1998. The role of microbial surface polysaccharides in the Rhizobium-legume interaction. Pages 73-116 in: Plant-Microbe Interactions: Subcellular Biochemistry, Vol. 29. B. B. Biswas and H. K. Das, eds. Plenum Press, New York.

Niehaus, K., Lagares, A., and Pühler, A. 1998. A Sinorhizobium meliloti lipopolysaccharide mutant induces effective nodules on the host plant Medicago sativa (alfalfa) but fails to establish a symbiosis with Medicago truncatula. Mol. Plant-Microbe Interact. 11:906-914.

Perotto, S., Brewin, N. J., and Kannenberg, E. L. 1994. Cytological evidence for a host defense response that reduces cell and tissue invasion in pea nodules by lipopolysaccharide-defective mutants of Rhizobium leguminosarum strain 3841. Mol. Plant-Microbe Interact. 7:99-112.

Price, N. P. J. 1999. Carbohydrate determinants of Rhizobium-legume symbioses. Carbohydr. Res. 317:1-9.

Quandt, J., and Hynes, M. F. 1993. Versatile suicide vectors which allow direct selection for gene replacement in Gram-negative bacteria. Gene 127:15-21.

Reed, J. W., Capage, M., and Walker, G. C. 1991. Rhizobium meliloti exo $G$ and exoJ mutations affect the ExoX-ExoY system for modulation of exopolysaccharide production. J. Bacteriol. 173:3776-3788.

Reuhs, B. L., Carlson, R. W., and Kim, J. S. 1993. Rhizobium fredii and 
Rhizobium meliloti produce 3-deoxy-D-manno-2-octulosonic acidcontaining polysaccharides that are structurally analogous to group II $\mathrm{K}$ antigens (capsular polysaccharides) found in Escherichia coli. J. Bacteriol. 175:3570-3580.

Sambrook, J., Fritsch, E. F., and Maniatis, T. 1989. Molecular Cloning: A Laboratory Manual, 2nd ed. Cold Spring Harbor Laboratory, Cold Spring Harbor, NY, U.S.A.

Schnaitman, C. A., and Klena, J. D. 1993. Genetics of lipopolysaccharide biosynthesis in enteric bacteria. Microbiol. Rev. 57:655-682.

Stevenson, G., Neal, B., Liu, D., Hobbs, M., Packer, N. H., Batley, M., Redmond, J. W., Lindquist, L., and Reeves, P. 1994. Structure of the $\mathrm{O}$ antigen of Escherichia coli $\mathrm{K}-12$ and the sequence of its $r f b$ gene cluster. J. Bacteriol. 176:4144-4156.

Strominger, J. L., Park, J. T., and Thompson, R. E. 1959. Composition of the cell wall of Staphylococcus aureus: Its relation to the mechanism of action of penicillin. J. Biol. Chem. 234:3263-3268.

Tsai, C.-M., and Frasch, C. E. 1982. A sensitive silver stain for detecting lipopolysaccharides in polyacrylamide gels. Anal. Biochem. 119:115119.

Van den Eede, G., Dreyfus, B., Goethals, K., Van Montagu, M., and Holsters, M. 1987. Identification and cloning of nodulation genes from the stem-nodulating bacterium ORS571. Mol. Gen. Genet. 206:291-299.
Van den Eede, G., Deblaere, R., Goethals, K., Van Montagu, M., and Holsters, M. 1992. Broad host range and promoter selection vectors for bacteria that interact with plants. Mol. Plant-Microbe Interact. 5:228-234.

Verma, D. P. S., and Hong, Z. 1996. Biogenesis of the peribacteroid membrane in root nodules. Trends Microbiol. 4:364-368.

Wang, Y., and Hollingsworth, R. I. 1994. The structure of the Oantigenic chain of the lipopolysaccharide of Rhizobium trifolii $4 \mathrm{~s}$. Carbohydr. Res. 260:305-317.

Wolucka, B. A., and de Hoffmann, E. 1995. The presence of $\beta$-D-ribosyl1-monophosphodecaprenol in mycobacteria. J. Biol. Chem. 270:20151-20155

Xiang, S.-H., Haase, A. M., and Reeves, P. R. 1993. Variation of the $r f b$ gene clusters in Salmonella enterica. J. Bacteriol. 175:4877-4884.

Yanisch-Perron, C., Vieira, J., and Messing, J. 1985. Improved M13 phage cloning vectors and host strains: Nucleotide sequences of the M13mp18 and pUC19 vectors. Gene 33:103-119.

Zhang, L., Al-Hendy, A., Toivanen, P., and Skurnik, M. 1993. Genetic organization and sequence of the $r f b$ gene cluster of Yersinia enterocolitica serotype O:3: Similarities to the dTDP-L-rhamnose biosynthesis pathway of Salmonella and to the bacterial polysaccharide transport systems. Mol. Microbiol. 9:309-321. 